\title{
Pergerakkan Darat Ikan Amfibi Andamia heteroptera Bleeker
}

\author{
GATOT NUGROHO SUSANTO ${ }^{1}$, FRANSISCA RESSA UTARI ${ }^{2}$ \\ ${ }^{1}$ Program Studi Biologi, Fakultas Bioteknologi, Universitas Kristen Duta Wacana \\ J1. Dr. Wahidin No. 5-25 Yogyakarta. 55224 \\ ${ }^{2}$ Program Studi Pendidikan Biologi, Fakultas Keguruan dan Ilmu Pendidikan, \\ Universitas Sanata Dharma \\ Jl. Afandi Gejayan, Mrican, Yogyakarta. 55002 \\ Email: mbahgatotnugroho@gmail.com
}

Received 30 January 2018; Received in revised form 1 February 2018;

Accepted 6 February 2018; Available online 9 May 2018

\begin{abstract}
Andamia heteroptera is amphibious fish that walk in land. That behavior used modification fins for terrestrial locomotion. The aim of the research is to identify locomotion of A. heteroptera in land and function of fins when used it for locomotion organ. The result shows that A. heteroptera used pectoral fins, pelvic fins, anal fin and caudal fin for locomotion organ. The sucker disk help for the movement. Caudal fin used for base organ when the fish was jump.
\end{abstract}

Keywords: Andamia heteroptera, amphibious fish, locomotion

\section{INTISARI}

Andamia heteroptera merupakan ikan amfibi yang bergerak di darat. Perilaku hidup A. heteroptera memerlukan modifikasi sirip sebagai organ lokomosinya agar mudah bergerak di darat. Tujuan dari penelitian ini adalah untuk mengidentifikasi pergerakkan A. heteroptera ketika berada di darat serta fungsi sirip sebagai organ lokomosi ketika berada di darat. Berdasarkan pengamatan A. heteroptera menggunakan sirip pektoral, sirip pelvik, sirip anal dan sirip kaudal untuk bergerak. Pergerakkannya di bantu oleh sucker disk, pelebaran mandibula. Sirip kaudal digunakan sebagai tumpuan ketika melenting untuk berpindah tempat.

Kata kunci: Andamia heteroptera, ikan amfibi, pergerakkan

\section{PENDAHULUAN}

Andamia heteroptera merupakan salah satu spesies ikan amfibi. Ikan amfibi didefinisikan oleh Gordon et al. (1969) sebagai ikan yang menghabiskan waktunya dengan keluar dari air atau berada di daratan sebagai bagian dari siklus hidupnya. Sayer dan Devenport (1991) menyebutkan bahwa secara umum ikan yang aktif keluar dari air atau melompat menuju daratan disebut ikan amfibi. Spesies ini aktif di darat dan jarang menghabiskan waktu lama di air. Andamia heteroptera dapat ditemukan di celah dan retakan batuan atau batuan yang terisolasi namun sering terkena deburan ombak (Susanto dan Soesilo, 2012). Ikan ini menghabiskan hampir sebagian besar hidupnya di darat. Susanto dan Soesilo (2012) menyebutkan bahwa ikan ini hanya memerlukan air untuk membasahi permukaan tubuhnya. Perilaku hidup $A$. heteroptera memerlukan modifikasi sirip sebagai organ lokomosinya agar mudah bergerak di darat. Tujuan dari penelitian ini adalah untuk mengidentifikasi pergerakkan A. heteroptera ketika berada di darat serta fungsi sirip sebagai organ lokomosi ketika berada di darat.

\section{METODE}

Penelitian ini dilakukan di batuan andesit yang terpapar ombak di pantai Gunungkidul, Yogyakarta. Pengamatan pergerakkan dilakukan secara langsung di lapangan dan di laboratorium dengan menggunakan akuarium. Pengamatan secara langsung dilakukan pada 
saat kondisi air laut surut. Pengamatan dilakukan pukul 08.00-12.00. Pengamatan di laboratorium dilakukan untuk mengetahui detail dari pergerakkan ikan. Pengamatan pergerakkan difokuskan pada organ gerak dan

\section{HASIL}

1

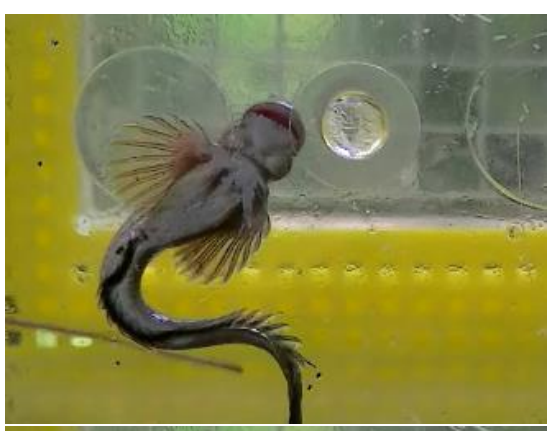

2
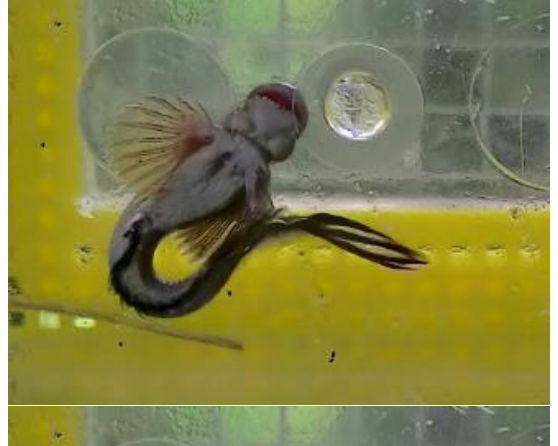

3

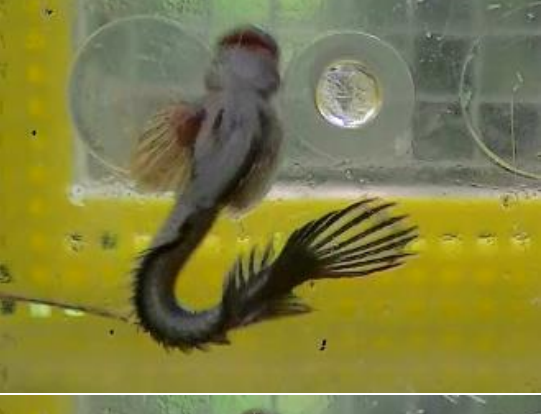

4

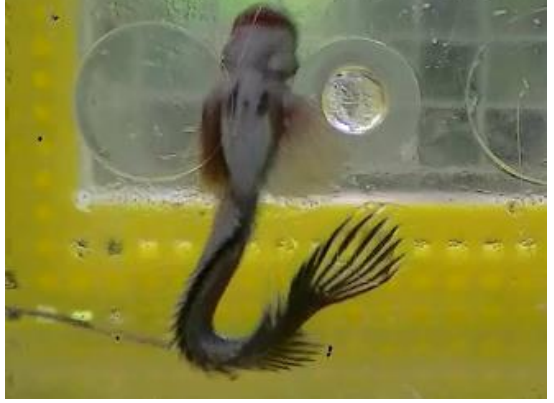

pergerakan badan. Dilakukan pengambilan video dan foto untuk memudahkan analisa. Hasil yang diperoleh kemudian dianalisa secara deskriptif.

6

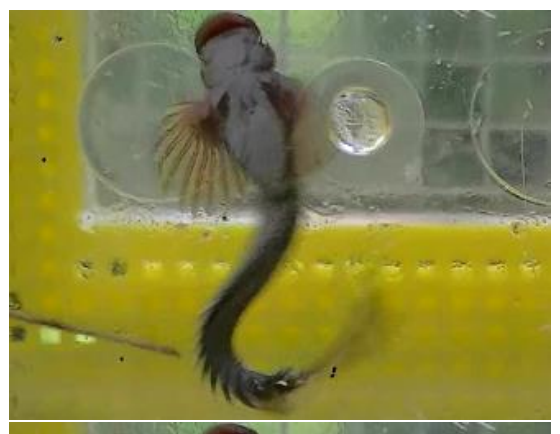

7

8
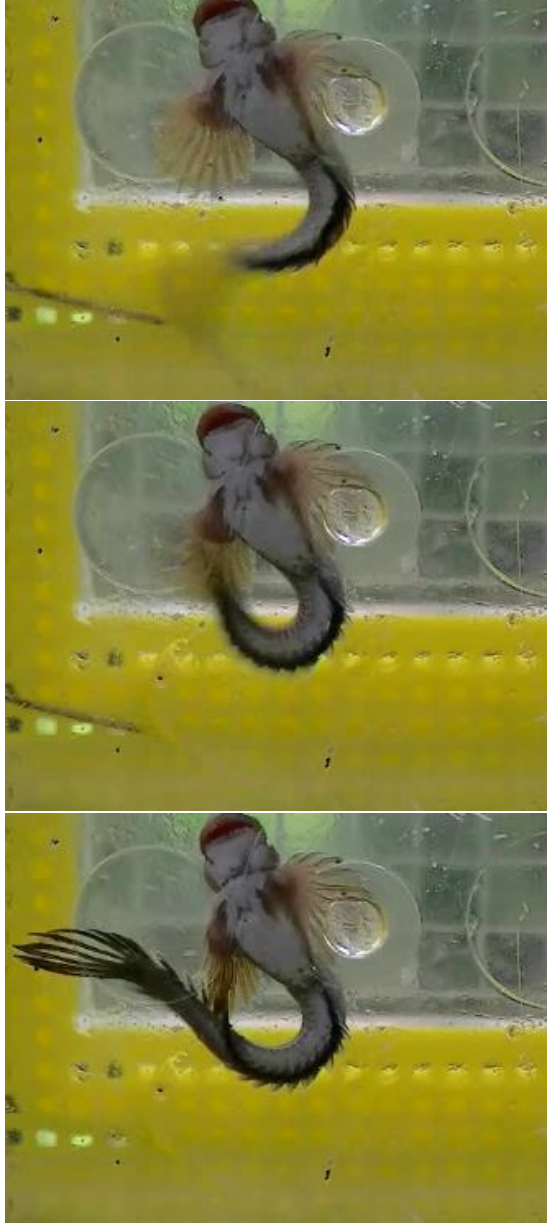


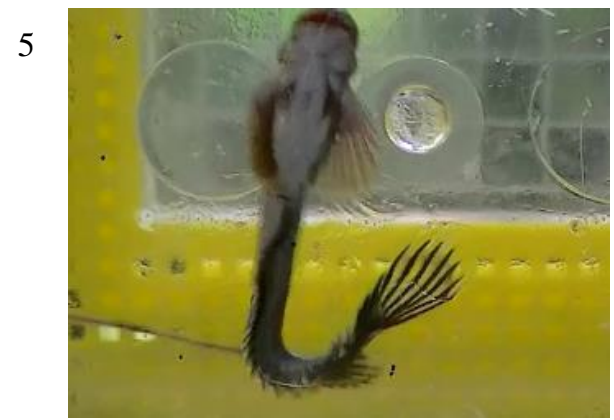

10

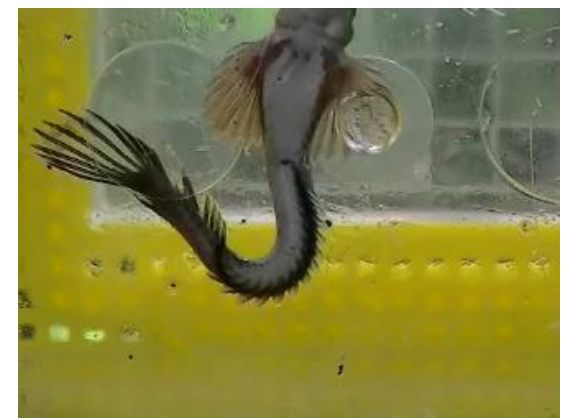

Gambar 1. Siklus pergerakan A. heteroptera pada dinding akuarium (1-10)

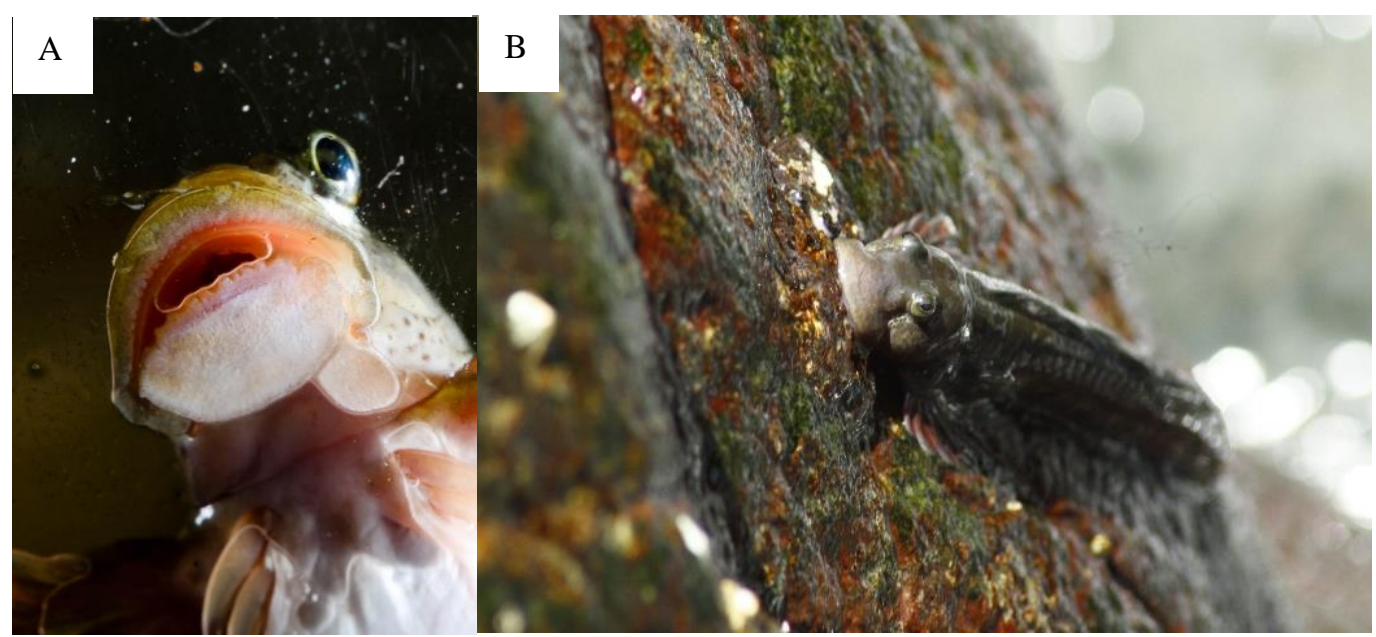

Gambar 2. Bentuk sucker disk pelebaran bibir posterior (A) dan posisi sucker disk ketika menempel di batuan (B).

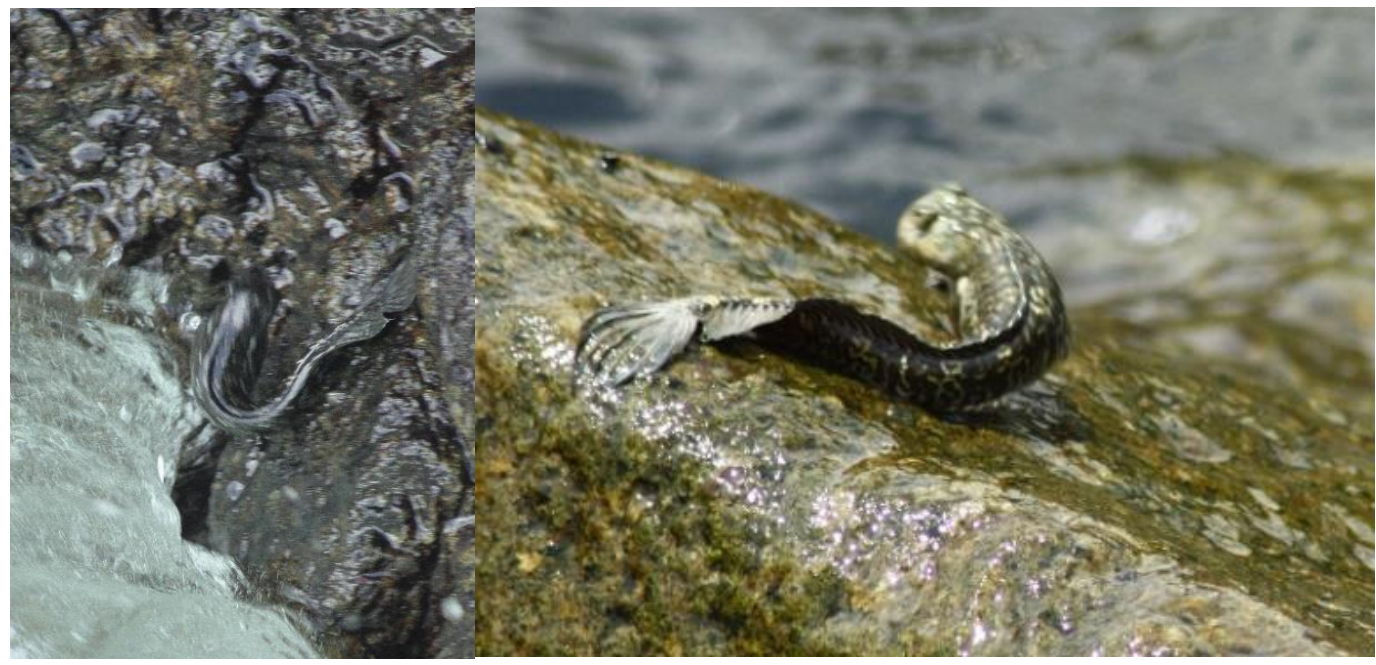

Gambar 3. Perilaku melenting A. heteroptera (A: tampak samping, B: di atas batu)

Andamia heteroptera menggunakan sirip pektoral, sirip pelvik, sirip anal dan sirip kaudal untuk bergerak di darat. Pergerakkan ikan ini dibantu sucker disk, pelebaran bibir bagian posterior, untuk menempel dan melekat di batuan (Gambar 2A). Andamia heteroptera menggunakan sucker disk serta sirip pektoral untuk menempel di batuan. Pergerakan A. heteroptera dimulai dengan melekatkan sucker disk pada substrat serta terbukanya jari-jari sirip pektoral. Bagian kauda akan membentuk menyerupai huruf "S" dengan sirip kaudal digunakan sebagai tumpuan. Sucker disk akan dilepaskan dari 
substrat ketika bagian kauda menyerupai bentuk "U" dan bagian sirip kaudal berada di samping sirip pektoral. Sirip kaudal digunakan sebagai tumpuan untuk mendorong tubuhnya maju ke depan. Sucker disk akan menempel ke substrat kembali setelah tubuh A. heteroptera terdorong ke depan dengan bagian kauda akan membentuk menyerupai huruf "L". Sirip pektoral dan sirip pelvik digunakan sebagai alat untuk menentukan arah pergerakan dari A. heteroptera. Bagian jari-jari sirip pektoral yang membuka digunakan sebagai penanda arah pergerakan A. heteroptera. Bagian kauda akan membentuk huruf "S" kembali setelah jari-jari sirip pektoral terbuka, sirip pelvik, dan sucker disk melekat ke substrat maka siklus pergerakan $A$. heteroptera di darat akan berputar kembali (Gambar 1).

Berdasarkan pengamatan, A. heteroptera berpindah tempat dengan menggunakan dua cara. Pertama, ikan ini akan berjalan di batuan dengan menggunakan sirip pektoral, sirip pelvik, sirip anal dan dibantu sucker disk. Kegiatan ini dilakukan untuk mencari makan atau berinteraksi sosial. Perilaku berpindah tempat yang kedua dengan melentingkan badannya (Gambar 3). Kegiatan ini dilakukan untuk berpindah ke batuan yang lebih jauh atau menghindari deburan ombak agar tidak terjatuh ke air. Perilaku ini bertumpu pada sirip kaudal sebagai organ tumpuan. Andamia heteroptera memiliki kelenturan badan untuk bergerak di daratan. Ikan ini memiliki kemampuan untuk meliukkan badannya hingga berbentuk "U" dan "S" agar memudahkannya bergerak di darat. Selain itu, habitat batuan menyebabkan ikan ini mampu menggerakkan badannya untuk melewati batuan. Fleksibilitas badan dari A. heteroptera ini dikarenakan ikan ini memiliki struktur zygapofisis di bagian vertebraenya sehingga memudahkah vertebrae bergerak secara fleksibel (Susanto dan Soesilo, 2012).

\section{PEMBAHASAN}

Andamia heteroptera menghabiskan sebagian besar waktunya di darat (batuan). Ikan ini menggunakan sirip pektoral, sirip pelvik dan sirip anal ketika berjalan di batuan.
Ekor (sirip kaudal dan caudal peduncle) digunakan sebagai penopang dan tumpuan ketika ikan ini berjalan atau berpindah tempat. Sucker disk, pelebaran mandibula, membantu mempermudah pergerakkan di darat. Selain itu, sucker disk berfungsi sebagai alat untuk menempel di batuan. Ketika terkena deburan ombak, sucker disk digunakan untuk menguatkan pegangan agar tidak terjatuh atau terseret ombak sehingga $A$. heteroptera tidak terjatuh ke air. Sucker disk akan diperlebar untuk menguatkan pegangan di batuan (Gambar 2B). Andamia heteroptera merupakan ikan yang masuk ke dalam kelompok skipper. Martin (1995) membagi dua kelompok skipper menjadi dua kelompok berdasarkan habitatnya, mudskipper (habitat lumpur) dan rockskipper (habitat batuan). Kedua kelompok ini menghabiskan sebagian besar hidupnya berada di darat. Habitat menentukan cara bergerak dan organ yang digunakan untuk bergerak. Periophthalmus gracilis, salah satu spesies mudskipper, menggunakan sirip pektoral, sirip pelvik dan caudal peduncle untuk membantu pergerakkannya (Susanto, 2016). Habitat batuan dari $A$. heteroptera (rockskipper) menyebabkan perlu adanya modifikasi dan tambahan organ pergerakkannya dibandingkan mudskipper. Kelompok ikan rockskipper menggunakan bagian sirip anal untuk membantu pergerakkan, sirip pelvik menempel di badan dengan badan sirip ramping serta sirip pektoral yang lebih lebar untuk menempel di batuan.

\section{KESIMPULAN}

Andamia heteroptera menggunakan sirip pektoral, sirip pelvik, sirip anal dan sirip kaudal untuk bergerak. Pergerakkannya di bantu oleh sucker disk, pelebaran mandibula. Sirip kaudal digunakan sebagai tumpuan ketika melenting untuk berpindah tempat.

\section{DAFTAR PUSTAKA}

Gordon MS, Boetius I, Evans DH, McCarthy R, Oglesby LC. 1969. Aspects of the physiology of terrestrial life in amphibious fishes. I. The mudskipper, 
Periophthalmus sobrinus. Journal Experimental Biology. vol 50: 141-149.

Martin KLM. 1995. Time and tide wait for no

fish: intertidal fishes out of water. Environmental Biology of Fishes. vol 44: 166-169.

Sayer MDJ and Davenport J. 1991. Amphibious fish: why do they leave water? Review in Fish Biology and Fisheries. vol 1: 159-181.
Susanto GN dan Soesilo NP. 2012. Struktur Skeleton Dan Otot Alat Gerak Serta Mekanisme Gerak Ikan Amfibi Periophthalmus gracilis Eggert (mudskipper) dan Andamia heteroptera Bleeker (rockskipper). [Tesis]. Yogyakarta: Universitas Gadjah Mada.

Susanto GN. 2016. Pergerakkan darat ikan amfibi, Periophthalmus gracilis Eggert. Jurnal Penelitian. vol 20(1): 36-39. 